\title{
Conditions Fostering International Graduate Students' Happiness and Engagement During the COVID-19 Pandemic
}

\author{
William S. Ankomah ${ }^{1, *}$ \\ ${ }^{1}$ Faculty of Education, Brock University, St. Catharines, ON, Canada \\ *Corresponding author: Faculty of Education, Brock University, St. Catharines, ON, Canada. E-mail: \\ william.ankomah@brocku.ca
}

Received: January 2, $2022 \quad$ Accepted: February 3, $2022 \quad$ Online Published: February 10, 2022

doi:10.5430/wje.v12n1p1 URL: https://doi.org/10.5430/wje.v12n1p1

\begin{abstract}
This paper focuses on eight conditions that kept international master's students (IMS) in a Southern Ontario university happy and engaged in their studies during the first and second waves of the COVID-19 pandemic. Using the first phase of the Appreciative Inquiry's (AI) 4-D cycle-i.e., discovery-this doctoral study conducted 14 individual interviews and three focus group discussions to identify conditions that made the IMS students happier and more engaged despite pandemic-related challenges. The study is crucial in advancing positive experiences of IMS because existing literature has focused primarily on their challenges and problems. The study's use of AI, a strength-based theoretical and methodological approach, suggests the need to highlight the quality experiences of this minoritized group. Data revealed specific factors that brought about happiness and boosted IMS engagement in their studies, namely: financial and emotional support from family; responsive instructors; employment opportunities during the pandemic; and learning and engaging in extracurricular activities with colleagues and friends. Other conditions also proved crucial to participants' happiness and engagement in their studies, including: professionalism of non-teaching staff; the institution's learning management system and supporting online platforms; virtual access to campus software and other learning resources; and reduced travel time. Study findings aim to inform international student policy and enrich the international student experience literature.
\end{abstract}

Keywords: appreciative inquiry, family, COVID-19 pandemic, international master's students, happiness, engagement

\section{Introduction}

This paper discusses eight factors that kept international master's student (IMS) participants of my doctoral study happy and engaged in their studies despite the challenges of the first and second waves of the COVID-19 pandemic. The literature on the IMS experience is rife with the challenges and problems they encounter. Challenges such as academic difficulties and uncertainties (Alqudayri \& Gounko, 2018; Chen \& Zhou, 2019), culture shock (Alqudayri \& Gounko, 2018; Brevetti \& Ford, 2017; Ge, 2021); language barriers (Burel, Graser, \& Park, 2019; Stegall, 2021), and racism and xenophobia (Chirikov \& Soria, 2020; Ge, 2021; Klodt, 2019) dominate the literature on international students' experience. Other negative factors include loneliness (Zhou, Liu, \& Rideout, 2017; Zhou \& Zhang, 2014), inability to interact and make friends with other students (Chirikov \& Soria, 2020; Watson \& Barton, 2020), travel restrictions and border closings (Beckstein, 2020; Watson \& Barton, 2020), and job losses (Beckstein, 2020; Watson $\&$ Barton, 2020). As Fischer (2020) and Watson and Barton (2020) point out, the challenges experienced by international students during the COVID-19 pandemic will persist post-pandemic (albeit unpredictable at the time of writing amidst a fourth wave of the pandemic); however, I argue that regardless of the challenges, IMS currently and will continue to have many quality schooling experiences that keep them spirited and motivated in their quest for prestigious foreign degrees. Therefore, it is vital that international education scholars consciously highlight and provide a more holistic picture of IMS' positive experiences to inform new policies and programs to foster positive change.

In the current literature, the positive experiences of international students are insignificant and lack depth. For example, support from family, course instructors, supervisors, and staff often are not highlighted as some of the 
conditions keeping international master's students engaged in their studies before and during the pandemic. In addition, making friends with both domestic and international students, finding part-time employment opportunities, and the engaging nature of graduate-level courses are all quality experiences that should be amplified in the literature to demonstrate the life-affirming conditions that help IMS persevere and enjoy their studies away from home. Also, institutional support - encompassing funding packages, scholarships, bursaries, and professional development workshops - is crucial to this student demographic's quality learning experiences and should not be taken for granted by students and scholars. Based on the present study's findings, I invite international student scholars to use strength-based approaches to investigate how the conditions noted above and discussed later in this paper promote the quality learning experience and well-being of international students.

As a former international student who had encountered challenges and positive experiences alike, I feel the conversation on international students' experience should be balanced because ultimately, scholars aim to use their studies not only to inspire quality service and best practices but also to sustain effective policies, practices, and programs. Therefore, (over)emphasizing what is not working well for IMS is not giving the complete narrative of their lived experiences. As a result, from the findings of this study, I argue that policymakers are not getting a holistic account of the overall IMS experience, and it is thus vital that scholars engage in strength-based research to identify what works well and discuss how existing and new conditions could be made better to inform policy and practice. Given the above premise, I elected to use AI as both a methodological and theoretical lens to inquire into what kept IMS at the sample institution (the pseudonymous University of Southern Ontario) happy and engaged despite the challenges of the COVID-19 pandemic. This paper sought to highlight the positive conditions that kept IMS happy and engaged in their studies in one of their most challenging academic and professional development moments. Also, another aim was to shift the narrative in the literature from the difficult experiences of IMS before and during the (ongoing) COVID-19 pandemic from a deficit lens to a more strength-based discourse to inform policy and practice. The research question that guided the discussion was: "As we are still experiencing the COVID-19 pandemic, what keeps you happy and engaged in your studies despite the challenges of the COVID-19 pandemic?" In what follows, I briefly present the AI methodology and theory, the research population and how participants were selected, the data collection methods, and data interpretation. Then I complete the paper with a discussion of the study's findings.

\section{Appreciative Inquiry Methodology and Theory}

Appreciative inquiry (AI) is a qualitative and strength-based approach to conducting research that draws attention to what works well in the object of inquiry, imagines how conditions could be improved, and designs concrete steps to take the individuals' or groups' vision to the desired level (Anderson, 2004; Collington \& Fook, 2016; Cooperrider \& Srivastva, 1987; Cooperrider, Whitney, \& Stravos, 2008; Kozik, 2018; Preston, 2017; Scott \& Armstrong, 2019). AI emerged in David Cooperrider's Case Western University dissertation (Bushe, 2011; Cockell \& McArthur-Blair, 2012; Hammond, 2013) and in Cooperrider and his doctoral supervisor Suresh Srivasta's paper titled "Appreciative Inquiry in Organizational Life." According to Cooperrider and Srivastva (1987), AI "refers to both a search for knowledge and a theory of intentional collective action which are designed to help evolve the normative vision and will of a group, organization, or society as a whole" (p. 152). In other words, as a methodology and change theory, AI consciously searches for data that give life to the phenomenon under study. With a focus on positive change and advancement of the normative vision of the group, the search for knowledge flows in the same continuum as the change efforts. For that to happen, Cooperrider and Whitney (2005) argue that "the questions we ask set the stage for what we find, and what we discover (the data) becomes the linguistic material, the stories, out of which the future is conceived and constructed" (p. 51). These scholars point out that current practices are informed by the questions and visions of those who constructed them. Therefore, it is vital to envision and ask questions to produce the desired results. Equipped with this knowledge, in the current study I used strength-based questions during the pandemic to discover the life-giving conditions that kept a vulnerable population on campus alive and motivated.

Nevertheless, despite the positive orientation of the AI methodology and theory, AI scholars argue that the approach does not ignore the problems; rather, it changes the conversation from negative issues and concerns to strength-based dialogues (Cockell \& McArthur-Blair, 2012; Cooperrider \& Whitney,2005). For example, according to Bushe (2001), the "appreciative process theorizes that you can create change by paying attention to what you want more of rather than paying attention to problems" (p. 122). To that effect, Bushe (2001) and other AI scholars argue that people generally become excited and receptive to new ideas and change when they see and feel valued by, for example, family members, institutions, or organizations. Conversely, AI scholars (e.g., Cockell \& McArthur-Blair, 2012; 
Cooperrider \& Whitney,2005) found that people get tired and feel frustrated or remain silent when what they do and suggest are not considered worthy. From the above, the message is that AI methodology and theory inspire individuals and organizations to collect data to identify what is working well for them and, most importantly, to grasp the collective vision needed to stimulate change in that direction. Consequently, by using AI in the current study, participants happily volunteered to share their invaluable narratives about the conditions that supported their learning despite the challenges of the pandemic.

The AI methodology flows through a 4-D cycle (discovery, dream, design, and destiny), but the process begins with identifying an affirmative or a strength-based topic that determines the scope of the inquiry (Bushe, 2011; Cooperrider \& Whitney, 2005). After contemplating a given affirmative situation, participants intentionally and actively discover the best of what works well, a stage Cooperrider and Whitney (2005) refer to as discovery. The cycle continues from the discovery to the dream stage, in which participants imagine the future they desire with positive images directing their vision. Then, during the design phase, participants consider their dream future to create concrete proposals (Bushe, 2011) or provocative propositions (Cooperrider \& Srivastva, 1987) for implementation. After the design stage is the destiny phase, when the group acts on the concrete propositions to turn their dreams into reality. The 4-D cycle does not end at the destiny phase, as the group and the leadership continue to "rediscover, redream, redesign as change happens" (Cockell \& McArthur-Blair, 2012, p. 30). I chose AI methodology and theory because of its ability to highlight success stories, encourage positive dreams, inspire inclusive and achievable actionable steps, and inform transformative change. As already stated, this paper comprises only the discovery phase of the AI model when the research question was asked. Findings from the dream and design phases will be available in future publications. Next, I present the research population and how participants were selected for the study.

\section{Research Population and Participant Selection}

The study's participants were all international students drawn from seven master's programs at the University of Southern Ontario. Participants were at different stages of their studies. First, 14 semi-structured individual interviews were conducted to obtain in-depth information about the object of inquiry. Then, after the private interviews, three open-ended focus group discussions involving 16 discussants were held to add depth and rigour and also ensure triangulation (Flynn et al., 2016) to enrich the data. The first and second focus groups had 5 participants each, and the third group was made up of 6 discussants. In all, 17 participants participated in both the individual interviews and focus group discussions, with 13 respondents taking part in both sessions. Using the snowball/referral sampling procedure, participants voluntarily reached out to participate after their friends informed them about the current research. The friends who referred their colleagues to participate had already participated and believed their colleagues and friends had information-rich data for the study (Creswell, 2013). According to Creswell (2013), the snowball "identifies cases of interest from people who know people who know what cases are information-rich" (p. 158) for a study. In this research, snowball sampling was very effective as one participant after another referred their colleagues to participate in the study to use their positive voices to inform policy and practice to improve the quality of their international education. Pseudonyms have been used to protect participants' identities and the institution where the study took place.

\section{Data Collection and Interpretation}

The COVID-19 pandemic shifted the study's initial plan from physical face-to-face to virtual data collection via Microsoft Teams. Studies by Creswell (2013), Donalek (2005), Kvale and Brinkmann (2009), and Salmons (2012) confirm that data collection via the internet is a valuable alternative to traditional face-to-face approaches once the parties have reliable computers and internet service. These scholars appreciate the cost and time effectiveness and the global reach of online platforms, and I too found the virtual format very helpful. For example, neither the participants nor the researcher incurred any traveling costs in this study. Instead, we agreed on a time that worked for both parties and held the interviews and discussions in the space and at the time of our choosing. The sound quality of the MS Teams recordings was excellent, and there was no noise or interference during the interviews. All 14 individual semi-structured interviews preceded the three focus group discussions during data collection. The same research question was asked in the semi-structured interviews and in the focus group discussions. An average of 1-hour was spent for each individual interview, and focus group discussions lasted 1.5 hours. After each focus group session, I shared the main discussion points for participants' approval, additions, and clarifications. Sim and Waterfield (2019) note that the debriefing phase of a focus group can "provide an opportunity for individual participants to raise 
concerns that may have been difficult to address during the group discussion" (p. 3018). Focus group participants in this study were generally satisfied with how their ideas were captured and did not add nor rescind any information. On the other hand, all individual interviews were transcribed, and transcripts were sent to participants for revisions to ensure the content accurately reflected their ideas and feelings. All but one participant corrected a grammatical error.

After the member checking, all transcripts were uploaded to NVivo software to code and establish themes for further analysis. As Fakunle and Pirrie (2020) and Williams and Moser (2019) share, NVivo qualitative data management software assists qualitative researchers in efficiently organizing, storing, coding, and analyzing data. In this study, I coded and established themes in the software and completed the analysis in MS Word. In NVivo, I read and re-read the transcripts several times while coding keywords and patterns to develop the codes, which were later collapsed to form the main themes of the study's findings. Data analysis was done in Word while the NVivo software housed the transcripts, international student and AI literature, and any document beneficial to the research. Next, I discuss the study's findings.

\section{Findings and Discussion}

This section discusses the findings from the individual interviews and focus group discussions. As already stated, the research question that guided this study was: "As we are still experiencing the COVID-19 pandemic, what keeps you happy and engaged in your studies despite the challenges of the pandemic?" In all, eight key themes (conditions) corresponding to what brought happiness to IMS and boosted their engagement in their studies emerged from the data: financial and emotional support from family; responsive instructors; employment opportunities during the pandemic; and learning and engaging in extracurricular activities with colleagues and friends. The remaining themes included: professionalism of the non-teaching staff; the institution's learning management system and supporting online platforms; virtual access to campus software and other learning resources; and reduced travel time to and from campus.

\subsection{Financial and Emotional Support from Family}

The data revealed that amid the COVID-19 pandemic, financial and emotional support from relatives kept IMS participants of this study happy and engaged in their studies. Participants shared that the continuous financial support from family members meant that regardless of circumstances such as the pandemic, isolation, and uncertainties, they knew their tuition fees and other financial obligations would be met. For example, Abhas (an Indian national in a professional master's program who paid three to four times more than domestic tuition) shared during an interview that family was his primary source of happiness and engagement in the program. He recognized that the financial help and regular video conversations from family gave him the energy and encouragement to concentrate on his studies. Abhas added that he did not worry unnecessarily about finances and the downturns of the pandemic because his relatives provided the support he needed, and all he had to do was stay safe and focused. Like Abhas and other individual interviewees, focus group members discussed that their relatives cared about their welfare and state of mind in these uncertain times. They agreed that their family members motivated them to stay on track in their academic and professional development in their respective programs because regardless of the difficulties of their relatives back home, the unconditional emotional and financial support remained unaffected. A Focus Group 2 (FG2) participant said, "it's like they share my challenges and frustrations with me, and most importantly, they continue to pay my expensive tuition and ancillary fees so I can fully concentrate on my studies."

In my interview with Shaiming (a Chinese national in an education program), she singled out and appreciated her husband's role during the pandemic. Shaiming shared her story about how her husband supported her:

Yeah, I would say that my husband has been so supportive, which brings me joy and keeps me engaged in my studies. He calls me every day. We have this time difference, which means that when it is 9:00 a.m. here, it is 9:00 p.m. in China, where he lives. So, as you can see, we have a 12-hour difference between us, but he does his best to make sure I am doing okay before he goes to bed or leaves for work. Sometimes, when I am having breakfast, he will be dozing off but will still video chat to keep me company, and I love that a lot.

As Shaiming's narrative demonstrates, family members go the extra mile to ensure that their relatives studying abroad are doing well emotionally and financially while away from home. Although there is limited literature on how family support during the ongoing COVID-19 pandemic has been beneficial to the happiness and engagement of international students in their studies, Ge (2021) and Raby, Ward, and Rhoades' (2021) respective studies identify the vital role of relatives to the positive schooling experience of international students. According to Ge (2021), 
"family connectedness [and] parental support ... were said to be helping participants [international students from China] overcome the negative effects associated with risks in the pandemic situation" (p. 598). In the current study, Shaiming, Abhas, and the participant in FG2 and the rest of the respondents were unequivocal about the immeasurable contributions of their families in their level of happiness and engagement during the pandemic. In line with Ge's (2021) study that explored "the lived experiences of Chinese international students at a Canadian university in COVID times" (p. 586), an unconditional family connection in the current study was significant to the IMS participants' well-being. This study's participants stayed in touch with family through regular video conversations, text messages, and direct phone calls to maintain and promote positive family-student-school relationships during one of this generation's most challenging times.

Another example of immeasurable family support came from Chaaya (an Indian national in a professional master's program). Chaaya paid tribute to her family during an individual interview:

I have a family that cares about my welfare, my state of mind in these uncertain times, and my academic progress in the program. The continuous support from family means a lot to me and knowing that I have such strong support keeps me happy and fully engaged in my studies.

From Chaaya's narrative of the family's role in the positive experience of international graduate students, regardless of status and background, family support remains crucial and decisive in the overall success and enjoyment of school. The data revealed that although they lived far away from their international student relatives, families always stepped in to provide the emotional and financial support to keep these students motivated, happy, and engaged in their studies abroad. The theme of financial and emotional support from family confirms a positive relationship between families and students as some families unconditionally ensured that their children received the best education regardless of location and the ongoing pandemic. It is also important to point out that positive relationships with relatives are significant factors in students' mental well-being and state of mind in the classroom. In that regard, this study agrees with Stevenson and Bland (2017) that it is imperative for policymakers to understand families' enormous influence on students' learning and schooling experience and use that understanding to design best practices that help students sustain the positive relationships they have with their relatives. Could reducing expensive international student tuition fees promote a healthier relationship among students, families, and institutions? I believe this question warrants further research to inform policy. Perhaps, lowering tuition could be crucial because, from the data, family members actively contribute to their international student relatives' emotional, financial, and social needs, and affordable tuition could be a welcome relief for international students and their families, strengthening their bond to positively affect institutions.

\subsection{Responsive Instructors}

Unanimously, participants reported enjoying their instructors' flexibility and accommodating approach since the beginning of virtual instructional delivery. Focus groups and individual participants alike mentioned that when the pandemic forced their institution to move instructional delivery online, they noticed a positive change in the instructor-student relationship. Participants used words such as "helpful," "calming," "welcoming," "accommodating," and "empathizing" to describe the overwhelming support their instructors gave them since classes moved online. They felt their instructors had compassion for students due to the uncertainties of the COVID-19 pandemic and hoped such welcoming change could be sustained post-pandemic. Using AI and positive psychology theories to ask strength-based questions amid a health pandemic allowed participants to reflect and pinpoint the encouraging transformation in the student-instructor relationship. In other words, by asking participants positive questions during one of the darkest moments of their studies, they were able to identify the enormous responsive considerations instructors gave to promote student learning. In FG1, a very satisfied participant shared their observation:

I want to add to the conversation that since the COVID-19 pandemic, I have noticed that my professors have been more respectful and kinder to students. It's like they understand the uncomfortable situation we are in. We are learning from home where there are many inconveniences from housemates and other sources. Therefore, I am happy that our instructors are doing their best to accommodate the challenges we face as international students. For example, the due date extensions on my assignments have been helpful in removing unnecessary pressures.

Using an AI lens, it is heartwarming to hear this study's participants experiencing global uncertainties away from home but discussing, appreciating, and enjoying the positive change in the pedagogical approaches of course instructors. As the participant in FG1 identified, learning from home could be chaotic for students who had not 
planned to work on their master's degrees online; however, the accommodation, kindness, and positive change in instructor-student relationships have been a boost for students' learning and mental health.

FG3 participants also acknowledged encouraging changes in their course instructors' communication and facilitation of their studies, which made them happy and engaged. Again, with an AI lens, I enjoyed listening to participants discuss how their instructors became more flexible in their teaching approach, giving students extra time to submit assignments, and sending emails to ask if they needed accommodation. For example, a participant in FG3 gave the following account:

Professors' understanding of the needs of our international student cohort is very commendable. Since the pandemic, instead of us writing exams, they now allow us to do more assignments that enable us to learn better. We take our time to research topics and submit our findings for professors' feedback. Compared to before the pandemic when we rushed to prepare and wrote many exams and later forgot many of what we learned, now, we are enjoying the flexibility the professors are giving us to explore different assignments and projects for assessment. Retention of knowledge is much better now, I would say.

In an individual interview, Praful (an Indian national in a physics program) spoke passionately about the positive change students are seeing in their learning relationships with course instructors:

Truly, the professors are doing a commendable job accommodating both international and domestic students. Even the international students who have gone back to their home countries are receiving support from their professors. It is fascinating that international students who went to their home countries because of the pandemic have their times for classes and assignments adjusted to suit their needs. Therefore, I think the professors are doing wonderfully well to support students learning in these challenging times.

The above positive accounts of participants indicate that international students were grateful to their instructors for being responsive to students' needs. From the positive narratives related to instructor support during the pandemic, I argue that such understanding of and responsiveness to IMS needs should be sustained because it is good for the mental health and overall well-being of not only the students but also the institution and host country. The responsive and positive rapport forged between IMS participants in my study confirms Chirikov and Soria's (2020) findings of their inquiry into "International Students' Experiences and Concerns During the Pandemic" that "instructors supported the remote learning" (p. 1) of international students, which the students greatly appreciated. Also, studies undertaken by Arkoudis, Dollinger, Baik, and Patience (2019), Stegall (2021), and Zhou et al. (2017) point out how their international student participants appreciated the helpful support of their course instructors. For example, in their study of the experiences of first-year Chinese international students in a Canadian institution, Zhou et al. (2017) reported that "participants highly commented on the program instructors. The words they used when they shared their impression about instructors included 'friendly,' 'humorous,' 'willing to help,' 'motivating and engaging students in class"' (p. 225). As already discussed, Zhou et al.'s findings align with the positive narratives of participants of the current study because they were all full of gratitude to their instructors for creating a conducive space for them to work at a pace that supported their learning. Yet the question remains: Why does the international student experience literature focus heavily on the challenges and problems of international students at the expense of life-giving stories? In this research, given the revelation that participants remained happy and engaged in their studies because of instructors' responsiveness to students' needs despite pandemic-related challenges, it is essential that policymakers sustain and improve professional development policies and programs currently in place.

\subsection{Employment Opportunities During the Pandemic}

The data also revealed that during the pandemic, participants remained happy and engaged in their studies because they still had part-time employment opportunities, which guaranteed them a steady flow of income to take care of necessities. In addition, the employment opportunities ensured that they continued to accrue Canadian work experience (a requirement on many job descriptions) and still advanced their studies in one of the most uncertain times of their international education. As part of their funding packages, three participants from Ghana were hired as teaching and research assistants in their respective faculties. In an individual interview, Eve (a Ghanaian national in the physical sciences) was thankful for the opportunities that her involvement in teaching and research assistant duties brought her during the pandemic:

I am grateful that in the pandemic, I can still do teaching and research assistant work to build my CV and raise money to support my international education. I wonder what I would have done without these jobs in this challenging period. As I already told you, my partial funding from the institution does not cover all the tuition I pay, so it is the teaching and research assistant work that help pay some of my tuition and other 
living costs. In fact, I feel very fortunate and happy, which is good for my studies, right? Also, both the teaching and research assistant works have taught me how to manage my time effectively, which I will forever be grateful for.

For Eve and other participants, it was not only the financial benefits and the work experience they cherished but also the demands of these positions that had taught them time-management skills that they believed were essential for their academic and professional endeavours. The narratives of Eve and other participants of the current research are congruent with Fakunle and Pirrie's (2020) study of the employability development opportunities of master's students in the United Kingdom; for example, Fakunle and Pierre found that participants in their study were aware "of the benefits of part-time work as a way of developing employability related skills, such as, organisation skills and time management" (p. 93). Clearly, employment opportunities for international students are crucial to their professional development, financial health, and study experience, and it is vital that institutional leaders and policymakers invest in programs that could hire IMS interested in working concurrently with their studies.

Besides the three respondents who received partial funding, the remaining participants were full fee-paying students and did not have funding packages that guaranteed teaching and research assistant positions. This meant that rather than securing teaching and research assistant opportunities in the institution, the full-fee paying participants typically got part-time non-teaching and research employment positions on- and off-campus. For example, during the discussions in FG2, a participant whose program did not provide teaching and research assistantship positions to international graduate students shared the following with colleagues:

Like all of you, I feared losing my part-time job at the big department store I work. Fortunately, all my international student friends still have our jobs, and we are so happy and thankful to the management for not laying us off. Now, I am enjoying my studies and working to make money to help offset some of my cost of living, and I am so happy about the opportunity. Also, the chance to talk to my colleagues at work on real-life events like sports and entertainment are game-changers for me. These conversations help take my mind of academic stuff for a moment and refresh me for later studies. I like the way it breaks the monotony of academic stuff.

The FG2 participant's happy feelings for still holding a part-time job in a challenging time were echoed by all discussants. I was not surprised because the research question was positively framed to get participants' positive feelings and experiences to enrich the literature and inform policy. It is also important to point out that participants in the current study as well as those in Fakunle and Pirrie's (2020) highlight the significance of using their part-time jobs to destress and recharge for better engagement with their schoolwork. In addition, as revealed in the current study, Fakunle and Pirrie's research also found that "these external opportunities for work experience could help international students to develop intercultural and interpersonal skills” (p. 93). Based on this study's findings as well as those of Fakunle and Pirrie, and also Ammigan (2019) and Calder et al. (2016), it is crucial that policymakers, institutional leaders, and governments come together to create adequate employment opportunities for both domestic and international students to address financial pressures and also give these students opportunities to build relationships with members of the community.

The data also revealed that participants greatly appreciated the Canadian government's regulation that allowed international graduate students to maintain gainful employment during their academic programs. For example, 11 of the 14 individual participants were definite about their gratefulness for the regulation that allowed them to work while in school, a conversation also picked up in all three focus groups. Unfortunately, existing literature does not account for how international graduate students appreciate the opportunity to combine their studies with paid employment. Instead, the narrative focuses on the lack of well-paying employment opportunities for international students (Altbach \& Knight, 2007; Ammigan, 2019; Ammigan \& Jones, 2018). For instance, Ammigan (2019) uses words such as "stress, anxiety, and depression" (p. 268) to describe the conditions of international students who struggle to find employment opportunities. Though I concede that some international students express frustration when they cannot secure employment opportunities during their studies, based on this study's findings and my own experience as a former international student seeking such work, I insist that the plight of these students is not as dire as portrayed in the literature. I argue that using such debilitating words (i.e., anxiety, depression, stress) to describe the international students' employment experiences feeds into the deficit narrative, making the international student experience appear both helpless and hopeless. Instead, while participants in my study acknowledged the challenges in obtaining jobs, they persevered and encouraged the government and institutional leaders to adopt new programs that create more employment opportunities for both domestic and international students.

In addition, Calder et al.'s (2016) study about housing, financial, and other obstacles facing Canadian higher 
education international students also uses a deficit approach to point out that these students are "underpaid for their qualifications" (p. 99). Of course, it is ethically wrong for employers to underpay their employees because of factors such as immigration status or background, and equitable wages should be paid to international students who elect to study and join the workforce. Still, rather than using a deficit lens to study international student experiences to suggest that there is nothing positive about the international student experience, the current study elected to use a strength-based approach to highlight conditions that kept international graduate students happy and engaged in their studies during the ongoing pandemic and the findings were encouraging. Clearly, participants yearned for better and more employment opportunities to sustain their international studies and give them some financial independence from their relatives, but as already stated, they expressed their full appreciation to the government and institutional leaders for providing opportunities to assume dual student-worker responsibilities. The findings of my data do not disagree that international graduate students become frustrated when they are underpaid or when employment opportunities are scarce; however, by responding to positive questions, participants were able to pinpoint that the chance to work on- and/or off-campus kept them happy and engaged in their studies regardless of the challenges in obtaining work. Instead of criticizing institutions and governments for not ensuring adequate employment opportunities, the current study's participants wanted the authorities to know how grateful they were for the opportunity and used their positive voices to ask leaders to do more to provide adequate employment opportunities for both domestic and international students who sought paid employment during their studies.

\subsection{Learning and Engaging in Extracurricular Activities with Colleagues and Friends}

Participants revered the opportunity to study with, befriend, and engage in extracurricular activities with diverse colleagues (Ammigan \& Jones, 2018; Amos \& Lordly, 2014; Guo \& Chase, 2011). The chance to make friends, share virtual learning spaces, play together in their small bubbles, and interact with various cultures enhanced many participants' quality learning experiences in their international studies. In addition, participants believed that engaging in similar activities with their colleagues promoted a feeling of connectedness, which kept them happy and engaged in their studies despite the challenges of international education and the pandemic. In terms of staying on top of their studies, all participants were grateful to their colleagues and friends for encouraging each other to, for example, prepare for class, complete and submit assignments on time, and ask for academic support when needed. By way of illustration, during FG1, a participant elaborated on the critical support his friends gave him to advance his studies. The participant shared the following with the group:

Sometimes, it is my housemates and friends who motivate me to learn. I see them studying, and I just join them. Actually, we have established a schedule where we meet in the common room and keep each other's company while learning our respective courses. There are six international master's students in my house, and we make friends. We study, cook, and play together, and it's really good for our studies and health in this COVID time.

In line with the literature (e.g., Ammigan \& Jones, 2018; Amos \& Lordly, 2014; Stevenson \& Bland, 2017), the narrative of the FG1 participant and colleagues confirm that positive relationships established with study mates, housemates, and program mates are essential for keeping IMS happy, motivated, and engaged in their studies, and the power of friendship should not be taken for granted.

In my interview with Chaaya, she also shared that her extracurricular activities with colleagues and housemates helped keep her composed and focused on the academic side of things. Chaaya narrated:

You know, the strict restrictions have been lifted, and now ten people can gather in a group. This has been good for my international colleagues and me because we meet regularly to play soccer and other sports to keep us healthy and refreshed. Right now, all our academic activities and jobs are online. Therefore, we get exhausted and stressed at times sitting in front of the screen. So, when everyone is done with their daily academic assignments and jobs, we get together at a nearby park and play for fun and keep our spirits high. The institution has also opened a few of their recreational facilities like the swimming pool, soccer field, and gym, so yeah, I go swimming to keep myself happy and composed for the challenging tasks ahead. We call our playtimes "stress-free time."

Indeed, as Chaaya observed, the stress-free times were packed with extracurricular activities that improved the mental and physical well-being of the IMS caught up in pandemic restrictions, making them feel refreshed, energized, and ready for the next academic and professional adventures. Contrary to the quality relationships forged between and among participants of this study, Watson and Barton (2020) reported that the international student participants in their study found it "especially difficult ... to form friendships, pursue existing friendships and to become part of society" (p. 110) during and after the lockdowns. While sympathizing with the gloomy situation reported by Watson 
and Barton, using an AI lens, I find it problematic that too much emphasis is placed on what is broken in the international student experience. As argued by AI scholars such as Cockell and McArthur-Blair (2012) and Cooperrider and Whitney (2005), the questions researchers ask are powerful because they determine the data that is derived to inform policy and programs. Using deficit-focused questions will reveal debilitating conditions of international students, which may influence policymakers and practitioners to operate with a deficit mindset and believe that the international student experience is a problem to be fixed. Meanwhile, amid the difficulties are uplifting stories about the development and sustenance of healthy student-student relationships. Therefore, to balance the problem-focus approach to advocating quality schooling experience for IMS, based on the findings of the current study and the suggestions of AI scholars (e.g., Bushe, 2011; Cooperrider \& Whitney, 2005; Hammond, 2013), I argue that researchers should unconditionally ask positive questions to generate strength-based data to inform policy and programs.

\subsection{The Professionalism of Non-Teaching Staff}

From the data, the professionalism of the institution's non-teaching staff, including those at the international student center, information and technology department, and career services, kept participants happy and engaged in their studies despite the challenges of the pandemic. Participants in both the focus group discussions and individual interviews were grateful to the professionals who worked tirelessly to support them with the needed information and advice on academic and professional development and decisions. Congruent with the findings of Ge's (2021) and Uusimaki and Garvis's (2020) respective international student experience studies, participants of my research were happy and engaged in their studies during the pandemic because they had a direct and reliable channel of communication and support that helped them navigate the challenging and uncertain times.

An important revelation in this study's data was how the department tasked with ensuring that international students received the necessary guidance and information on all immigration and visa documentations worked assiduously to ensure that students continued to receive quality academic, language, and visa support regardless of the pandemic-related challenges and uncertainties. For example, a participant in FG3 made the following contribution:

Regularly, the international student center organizes seminars on immigration services for us. In these seminars, they talk about study permit extensions, work permits, and permanent resident applications. They also answer our questions on other immigration documents. A few days ago, I received an email asking international students to attend four such seminars. The help from the international department keeps me happy and engaged in my schoolwork because I know they are always there to make us feel comfortable and remain legal in our international studies.

The FG3 participant made a crucial observation and recognized the importance of international students maintaining their legal status while studying in a foreign country. To this participant and colleagues, receiving answers to their questions and obtaining the needed information from the international department helped them stay calm and maintain their focus in the face of global uncertainties. The findings of my study about staff support confirm Zhou et al.'s (2017) study of the experiences of Chinese international students at a Canadian university. Zhou et al.'s pre-pandemic study reported that participants appreciated the international student office's extra efforts to ensure international students' needs were met. According to Zhou et al., the international student office "provided significant assistance to international students by providing various services or workshops that helped with applying for a US visa, applying for work permits, job hunting, and English conversation skills" (p. 222). Based on Zhou et al.'s study and the findings of the current research, I argue that international education scholars should begin asking strength-based questions to generate valuable data highlighting what works well and how current policies and programs could be enriched to create a win-win outcome for IMS and the institutions that host them.

Like the positive experiences of their colleagues, Praful (a Science student from India) and Evans (an Arts student from Ghana) shared in their respective interviews that the technical support from the information and technology (IT) folks kept them happy and engaged in their studies. These participants praised the professionalism of the IT personnel for ensuring that the institution's learning and management systems worked effectively without any hiccups. For example, according to these participants, when classes moved online due to the restrictions on face-to-face instructional deliveries, they received regular guidance and technical support from their respective departments and institutional IT teams about how each online platform available to them functioned. They were also happy that the IT professionals gave students synchronous and asynchronous video tutorials and lectures to prepare them for online lessons. In addition, the data also revealed that participants very much appreciated how the IT support stayed on standby to help instructors who needed help to navigate the online teaching platform. The smooth 
and uninterrupted instructional delivery and virtual and remote access to software fostered participants' learning in the pandemic, keeping them happy and engaged in their studies.

Participants also indicated that the institution's career services offerings helped meet their needs, which kept them happy and engaged in their studies during the pandemic. Although this study's participants wished the career services did more than they did at the time of data collection, all participants found the resumé and cover letter writing workshops activities and assistance from the center very beneficial to their job search. For example, a participant in FG2 added to the conversation with the following:

For me, the employees at the career help center have been very good at organizing workshops to assist students in revising the resumés and cover letters so we can be ready to apply for co-op and jobs when there are postings. You know, because of the COVID-19 situation, everything is online. Still, it is exciting to see the amount of effort they are putting in to help us with the techniques and tips to convince employers that we have the right knowledge and skillset to promote their work. In addition to the workshops where they work one-on-one with students, they also send us information through emails about the opportunities they are receiving.

The contributions of this FG2 participant support AI scholars' argument that innovative and positive data about the object of inquiry could be obtained to advance the development of individuals, groups, and institutions by asking strength-based questions. Furthermore, as confirmed in this study, the international student, IT, and career services offices continued to give international students the quality support services they offered prior to the pandemic, revealing how the institution's staff upheld their ethical and professional standards regardless of challenges.

\subsection{The Institution's Learning Management System and Supporting Online Platforms}

The current study's institution uses open-source educational software (i.e., Sakai) as its learning management system (LMS) to foster teaching and learning. The Sakai software is free, and institutions can adapt it to suit their needs. Due to the COVID-19 pandemic, the institution also encouraged instructors to use MS Teams and Lifesize platforms to deliver instructions to students while giving them informal opportunities to interact and engage in virtual face-to-face discussions, among other things. Research participants recognized the influential role these online learning platforms played towards the end goal of obtaining their master's degrees. They appreciated the chance to continue their international education without interruptions because, as international students, each day in Canada comes with an extra financial cost. Hence, fewer (or no) disruptions of their academic progress was a welcomed development in the middle of global uncertainties. Overall, participants expressed satisfaction and happiness with the institution's online learning platforms and emphasized that the effectiveness of the platforms made them happy and got them excited about their studies. They agreed that there had been no interruption to their studies and were excited about the opportunity to complete their programs on time. During FG1, a participant said that the "online learning platforms have been great. We use it for lectures, group projects, and all kinds of class activities. Our case analysis and presentations are still effective, and we can still engage actively in class activities." The narratives during the individual interviews were in line with the focus group discussions. For example, during our interview session, Vihas (an Indian national in a professional master's program) said, "I find the institution's online learning platforms effective and reliable. This means that our synchronous and asynchronous sessions are uninterrupted and smooth. I am enjoying the discussions and the occasional case studies we do." Vihas' observation was echoed in all three focus groups, and it is also congruent with the findings of Chiriko and Soria's (2020) study which reported that international students of their research adapted well to virtual learning and were "more satisfied with how their university responded to the pandemic" (p. 1).

From the data, it was evident that participants preferred an in-person classroom environment. Still, they were happy that the quality of instructions and learning had not been compromised online. Initially, some participants had doubts about the effectiveness of the solely online teaching and learning process. However, at the time of data collection, participants had adjusted to and embraced the institution's temporary measures that ensured student progress was not delayed because of the pandemic. Among the participants, even the most skeptical critic of virtual learning found it faultless and had this to say:

I'm a person who really liked the face-to-face more, and I was not too fond of online learning because I thought it was boring. I like to mingle with people. I want to see people in real life instead of virtually, but I want to say that I am so grateful to all the professors for the efforts they have put in to ensure that their online platforms are engaging, effective, and fun for us. I don't see any difference between the in-person and online lessons in terms of my academic work. However, I really miss hanging out with my friends before and after classes. (Participant, FG2) 
The skepticism of the FG2 participant was not misplaced at all. Most of the participants expressed that although their academic work was progressing well, they missed the opportunities face-to-face instructional delivery offered. However, it is also essential to underscore that participants recognized and credited their instructors for making online learning engaging and fun for students.

In contrast to participants who could not wait to return to the physical classroom, the data also revealed that other respondents longed for school systems that allowed students to study from home and other designated places. For example, in one of the individual interviews, Chaaya did not hide her unhappiness about going for lectures and seminars in the pre-pandemic physical classroom nor her delight in virtual learning during the pandemic:

I'm not too fond of the physical classroom format of teaching and learning. I have never been a fan of the classroom format because I think it is an old-fashioned way of organizing school. When classes moved online, I have seen that I am doing very well in my studies. You know, I am saving a lot of time. I don't have to get up earlier than normal, devour my breakfast, and hurry to the bus stop to catch the campus bus. It's as if a heavy load has been lifted off my shoulders. I wake up every day feeling better. I love the chance to be in a synchronous session so I can interact with professors and my classmates. I also love the asynchronous platform on Sakai. We use the forum and charts on Sakai to respond and share ideas. In fact, life is much better for not going to the physical class. I am still meeting and making friends with my colleagues online. We are using breakout rooms or our own selected times and platforms to do group work.

Chaaya's positive account about learning online resonated with other participants, such as Shaiming, who was grateful to the institution for quickly and efficiently adjusting and adopting virtual learning platforms to support student learning. During an interview, Shaiming praised the university's efforts: "I think the institution has done well by allowing students to continue their studies through various online platforms that are easy to navigate, and they have been a tremendous technological resource for this COVID-19 moment." Such findings demonstrate that when the COVID-19 pandemic forced in-person classes to move online, the institution's LMS, MS Teams, and Lifesize platforms ensured students continued to receive quality instruction from instructors who kept participants happy and engaged in their studies. Although most participants missed in-person classes, others felt the virtual schooling allowed them to enjoy their studies in the comfort of their homes. The shining light in participant stories was that the institution's LMS and supporting virtual platforms worked well to guarantee the successful and timely completion of their master's programs.

\subsection{Virtual Access to Campus Software and Other Learning Resources}

The data revealed that virtual access to campus software and other learning resources kept participants happy and engaged in their studies. Primarily, professional programs and physics participants needed virtual access to specific software. Fortunately, their respective programs ensured that students had unfettered access to relevant software such as Python, R, and Power BI to complete their individual and group assignments. For example, a FG1 participant from the professional program said, "I appreciate the virtual labs and the programming languages we have. These are free for us, and we use them greatly because it is the same language the industries use. I am pleased about that." In other words, although students could not access the physical laboratories due to the pandemic restrictions, this participant was excited about the opportunity to freely access software already used by potential employers. This meant that international students continually received the quality education they paid for and are happy about the measures put in place by their programs and institution to ensure that students stay up to date in their knowledge and skill development regardless of global uncertainties. Sahas (an Indian national in a professional master's program) acknowledged in an individual interview the critical role that the easy access to business software was playing for his studies: "Another resource that is helping my studies and working well for me is the remote access to different software for our studies. For example, we have free access to Citrix, which enables us to run applications remotely."

In addition to the virtual access to the campus laboratory, the institution allowed some students to physically access the campus laboratory on a case-by-case basis. One such student was Sajag (an Indian national in the physis program). According to Sajag, his studies had not been interrupted because he could access the software he needed for his studies virtually and physically on campus. Hence, he felt fortunate and appreciated all the necessary measures the institution and the program took to ensure that students were safe when they came to campus. During his interview session, Sajag added to an earlier point with the following:

The opportunity to use both the on-campus and virtual laboratories to continue with experiments has been beneficial. As I already told you, due to the COVID-19 scare, the institution has imposed restrictions on face-to-face interactions on campus, which affected our initial use of the campus laboratory for 
experiments. Thankfully, the leaders have found a way around that, so they allow individual students to come to the laboratory one at a time. I can do most of my academic work virtually and come to campus only to do more hands-on activities.

The above stories of participants are evident that respondents significantly valued the chance to access relevant software remotely and physically, keeping them happy and engaged in their studies. It is also important to underscore that students shared how well they were received to the physical laboratory with all COVID-19 protocols observed to keep everyone involved safe.

\subsection{Reduced Travel Time}

It was unanimous among participants that the reduced travel time to and from campus had been significantly beneficial to their studies. As in Beckstein's (2020) research, participants in the current study noted less stress in attending classes because all they needed to do was turn on their laptops, log in to their student accounts, and connect to the synchronous class. Alternatively, the asynchronous sessions meant that they could participate in discussions and lessons on their own terms. Also, respondents noted flexibility in the clothes they wore and the location from which they attended class. During the discussions in FG1, a participant was excited about the opportunity the little to no travel time gave him:

I am happy because I don't have to stress getting to class so early in the morning, rushing through breakfast, and running to the bus station. Now, there is no traveling from my house to school and back. I don't have to walk from one classroom to another. I don't wait for my turn to use the toilet. Everything is right here in my house, and I am spending quality time on my schoolwork. Although I miss the physical classroom so much, I am happy with the flexibility the virtual learning has brought to me.

From the FG1 participant's account, respondents were happy to save time on things that limited their learning opportunities and used the extra time to engage in wide-ranging activities. As highlighted by most of them, they invested the saved time on studies, play, and rest. For example, Amogha shared the following in our interview session:

The first thing I want to talk about is the travel time. Right now, there is no traveling to and from campus, which is a huge benefit to students. Of course, I really miss the face-to-face interactions with colleagues; however, I am also enjoying the zero travel. You know, I don't have to rush to dress up, leave for the bus stop, and walk across campus for classes. I am happy to share with you that I submit all my assignments before due dates, and I am taking some free online courses on Coursera and LinkedIn because of the extra time I have. Guess what? I also got myself part-time employment in a nearby Tim Hortons to experience some Canadian culture while making some income. So, yes, I am very happy to have enough time to do different things to develop my academic and professional life.

As indicated in Amogha's story, participants miss the face-to-face interactions they had in the physical school, but at the same time, they were excited by and making the most of the reduced travel time.

In addition to some participants spending their extra time on free online courses and part-time employment opportunities, others used the time to engage in sporting activities with housemates to improve their physical and mental health. In that regard, Ranajay admitted in our interview that he was a sports fan and liked playing all kinds of sports with housemates and other friends in his bubble to improve their physical health and reduce stress:

Sporting activities have been beneficial in this COVID-19 time for me. I get most of my studies done during the day and play soccer, volleyball, badminton, and other sports every evening with my housemates. With online courses, I have been able to find a good balance between physical activities and academic life, which is very good for my health. I have channeled all the time I spent preparing for campus, waiting for the bus, traveling to campus for class and group projects into my studies and playtime. Of course, I miss campus so much, especially meeting my old friends and making new ones and spending some time chatting, eating, and learning. However, the restrictions have opened up another opportunity for me to study hard at home and enjoy some exercises to improve my mental and physical well-being. By the way, I get good sleep, too.

While Ranajay uses his saved time to engage in sporting activities with friends, Jaival was happy to read nonfiction books to expand his imagination and improve his English reading, speaking, and writing skills. During an interview, Jaival shared how he was spending his extra time:

One more positive thing that I want to mention is that I have been using some of my free time to read 
many nonfictional books. As I said earlier, I am an avid reader, so I read books to expand my imagination and thinking anytime I get the chance. Reading books also helps me improve my speaking and writing in the English language, and I am happy with the number of books I've read in this COVID period.

Besides the various ways participants expressed using their saved time, a participant in FG3 admitted being lucky because he was using some of his saved time to receive direct support from his MBA housemate on a career interest he has in finance:

Luckily, I am fortunate enough to have my friend around who is supporting me and vice versa in these uncertain times. The ray of hope and ray of light has been my MBA friend helping me learn new things and acquiring new skills for an interest I have in finance. As I mentioned earlier, I come from a hard-core physics and mathematics background, but I want to get into finance. However, it was a problematic situation for me because I did not know about finance. So, interacting with my housemate and my friends who are doing their master's degrees in MBA and finance has given me the golden opportunity to learn many things I thought were impossible. With assistance from my friends, I spend an immense amount of my spare time going through many online lectures about finance.

From Amogha, Ranajay, Jaival, and the FG3 participant's narratives, it was clear that the reduced travel time to and from campus has allowed international students to invest adequate time in their studies with time to spare on other extracurricular activities to boost their overall mental and physical health. As participants shared and discussed their stories, they were grateful for the study's research question because, as one participant acknowledged, she did not know that she was making good use of her saved time. The question reminded her to do more and pay attention to how she was spending the extra time at her disposal.

\section{Conclusion}

This study used an AI lens to discuss eight conditions that kept international master's students at the University of Southern Ontario happy and engaged in their studies despite the challenges of the first and second waves of the COVID-19 pandemic. The strength-based approach allowed participants to use a positive lens to share their life-affirming stories to answer the study's research question. Conditions that brought happiness and boosted IMS engagement in their studies included financial and emotional support from family; responsive instructors; employment opportunities during the pandemic; and learning and engaging in extracurricular activities with colleagues and friends. Other conditions that fostered IMS happiness and engagement in their studies away from home included the professionalism of non-teaching staff; the institution's learning management system and supporting online platforms; virtual access to campus software and other learning resources; and reduced travel time. The findings of this study confirm Cooperrider and Whitney's (2005) argument that:

Building and sustaining momentum for change requires large amounts of positive affect and social bonding - things like hope, excitement, inspiration, caring, camaraderie, sense of urgent purpose, and sheer joy in creating something meaningful together... The major thing a change agent can do that makes a difference is to craft and ask unconditionally positive questions. (p. 53)

Based on Cooperrider and Whitney's call and the findings of this research, I encourage fellow international education scholars to frame positive questions to help identify the conditions that work well for international students, the dream experiences they wish for, and how they believe those dreams could be realized. Policymakers and institutional leaders would do well to use the findings of this study to help strengthen existing programs and create new policies to give international master's students a high-quality schooling experience.

\section{References}

Alqudayri, B., \& Gounko, T. (2018). Studying in Canada: Experiences of female graduate students from Saudi Arabia. Journal of International Students, 8(4), 1736-1747. https://doi.org/10.5281/zenodo.1468077

Altbach, P. G., \& Knight, J. (2007). The internationalization of higher education: Motivations and realities. Journal of Studies in International Education, 11(3/4), 290-305. https://doi.org/10.1177/1028315307303542

Ammigan, R. (2019). Institutional satisfaction and recommendation: What really matters to international students. Journal of International Students, 9(1), 262-281. https://doi.org/10.32674/jis.v9i1.260

Ammigan, R., \& Jones, E. (2018). Improving the student experience: Learning from a comparative study of 
international student satisfaction. Journal of Studies in International Education, 22(4), 283-301. https://doi.org/10.1177/1028315318773137

Amos, S., \& Lordly, D. (2014). Picture this: A photovoice study of international students' food experience in Canada. Canadian Journal of Dietetic Practice and Research, 75(2), 59-63. https://doi.org/10.3148/75.2.2014.59

Anderson, E. C. (2004). What is strengths-based education? A tentative answer by someone who strives to be a strengths-based educator. Retrieved from https://www.weber.edu/WSUImages/leadership/docs/sq/strengths-base-ed.pdf

Arkoudis, S., Dollinger, M., Baik, C., \& Patience, A. (2019). International students' experience in Australian higher education: Can we do better? Higher Education, 77(5), 799-813. https://doi.org/10.1007/s10734-018-0302-x

Beckstein, A. (2020, July 24). How are international students coping with the covid-19 pandemic? The Student. Retrieved from https://www.timeshighereducation.com/student/blogs/how-are-international-students-coping-covid-19-pandemi $\mathrm{c}$

Brevetti, M., \& Ford, D. (2017). Debates on the international student experience: Schools as a morally formative culture. Journal for Multicultural Education, 11(3), 189-193. https://doi.org/10.1108/JME-08-2016-0044

Burel, M., Graser, M., \& Park, S. (2019). Exploring the international student experience: Providing insight through a mixed-methods approach. Journal of Library Administration, 59(2), 149-174. https://doi.org/10.1080/01930826.2018.1562804

Bushe, G. R. (2001). Five theories of change embedded in appreciative inquiry. In D. Cooperrider, P. Sorenson, D. Whitney, \& T. Yeager (Eds.), Appreciative inquiry: An emerging direction for organization development (pp. 117-127). Champaign, IL: Stipes.

Bushe, G. R. (2011). Appreciative inquiry: Theory and critique. In D. Boje, B. Burnes, \& J. Hassard (Eds.), The Routledge companion to organizational change (pp. 87-103). Oxford, UK: Routledge.

Calder, M. J., Richter, S., Mao, Y., Kovacs Burns, K., Mogale, R. S., \& Danko, M. (2016). International students attending Canadian universities: Their experiences with housing, finances, and other issues. Canadian Journal of Higher Education, 46(2), 92-110.

Chen, J., \& Zhou, G. (2019). Chinese international students' sense of belonging in North American postsecondary institutions: A critical literature review. Brock Education: A Journal of Educational Research and Practice, 28(2), 48-63. https://doi.org/10.26522/brocked.v28i2.642

Chirikov, I., \& Soria, K. M. (2020). International students' experiences and concerns during the pandemic. Berkeley, CA: UC Berkeley, Center for Studies in Education. Retrieved from https://cshe.berkeley.edu/seru-covid-survey-reports

Cockell, J., \& McArthur-Blair, J. (2012). Appreciative inquiry in higher education: A transformative force. San Francisco, CA: Jossey-Bass.

Collington, V., \& Fook, J. (2016). Instigating change through appreciative inquiry: A case study. International Journal of Higher Education Management, 3(1), 1-13.

Cooperrider, D. L., \& Srivastva, S. (1987). Appreciative inquiry in organizational life. In W. Pasmore \& R. Woodman (Eds.), Research in organizational change and development (Vol. 1, pp. 129-169). Greenwich, CT: JAI Press.

Cooperrider, D. L., \& Whitney, D. (2005). A positive revolution in change: Appreciative inquiry. San Francisco, CA: Berrett-Koehler.

Cooperrider, D. L., Whitney, D., \& Stravos, M. J. (2008). Appreciative inquiry handbook: For leaders of change (2nd ed.). Brunswick, $\mathrm{OH}$ : Crown.

Creswell, J. W. (2013). Qualitative inquiry and research design: Choosing among five approaches. Thousand Oaks, CA: SAGE.

Donalek, J. G. (2005). The interview in qualitative research. Urologic Nursing, 25(2), 124-125.

Fakunle, O., \& Pirrie, A. (2020). International students' reflections on employability development opportunities during a one-year masters-level program in the UK. Journal of International Students, 10(S2), 86-100. https://doi.org/10.32674/jis.v10iS2.2719 
Fischer, K. (2020). Confronting the seismic impact of COVID-19: The need for research. Journal of International Students, 10(2), i-ii. https://doi.org/10.32674/jis.v10i2.2134

Flynn, T., Wideman, R., Stagg-Peterson, S., Bruce, C., Windle, S., Bennett, J., \& McAdie, P. (2016). Learning through teacher research: A guidebook for your action research journey. Toronto, ON: ETFO.

Ge, L. (2021). A hermeneutic phenomenological inquiry at a Canadian university: Protective and risk factors for Chinese international students in COVID times with gender comparison. Journal of International Students, 11(3), 586-607. https://doi.org/10.32674/jis.v11i3.2218

Guo, S., \& Chase, M. (2011). Internationalisation of higher education: Integrating international students into Canadian academic environment. Teaching in Higher Education, 16(3), 305-318. https://doi.org/10.1080/13562517.2010.546524

Hammond, S. A. (2013). The thin book of appreciative inquiry (3rd ed.). Bend, OR: Thin Book.

Klodt, L. A. (2019). The experience of international students in Ontario universities [Master's thesis, Brock University]. Brock University Digital Repository. Retrieved from https://dr.library.brocku.ca/handle/10464/14082

Kozik, P. L. (2018). Can appreciative inquiry increase positive interactions, student self-advocacy and turn-taking during IEP meetings? Journal of Research in Special Educational Needs, 18(2), 114-123. https://doi.org/10.1111/1471-3802.12398

Kvale, S., \& Brinkmann, S. (2009). Interviews: Learning the craft of qualitative research interviewing. Thousand Oaks, CA: SAGE.

Preston, J. P. (2017). Insight from Nunavut educators using appreciative inquiry. Alberta Journal of Educational Research, 63(3), 233-248.

Raby, R. L., Ward, R., \& Rhoades, G. (2021). Listening to the voices of students who studied abroad: Students and their agency to maximize their abroad experiences. Journal of International Students, 11(3), 628-646. https://doi.org/10.32674/jis.v11i3.2857

Salmons, J. (2012). Cases in online interview research. Thousand Oaks, CA: SAGE. https://doi.org/10.4135/9781506335155

Scott, J. T., \& Armstrong, A. C. (2019). Disrupting the deficit discourse: Reframing metaphors for professional learning in the context of appreciative inquiry. Professional Development in Education, 45(1), 114-124. https://doi.org/10.1080/19415257.2018.1452780

Sim, J., \& Waterfield, J. (2019). Focus group methodology: Some ethical challenges. Quality \& Quantity, 53(6), 3003-3022. https://doi.org/10.1007/s11135-019-00914-5

Stegall, J. (2021). Peaks and valleys: The lived experiences of international students within an English immersion program using the integrated skills approach. Journal of International Students, 11(3), 723-741. https://doi.org/10.32674/jis.v11i3.2395

Stevenson, J., \& Bland B. (2017, July). Mobilising family support: Implications for the academic resilience of international students. London, UK: UK Council for International Student Affairs. Retrieved from http://shura.shu.ac.uk/16332/1/UKCISA\%20Final\%20report\%202017.pdf

Uusimaki, L., \& Garvis, S. (2020). Reflections of learning experiences of international students in Sweden. Journal of International Students, 10(S2), 36-50. https://doi.org/10.32674/jis.v10iS2.2757

Watson, M., \& Barton, G. (2020). Using arts-based methods and reflection to support postgraduate international students' wellbeing and employability through challenging times. Journal of International Students, 10(S2), 101-118. https://doi.org/10.32674/jis.v10iS2.2849

Williams, M., \& Moser, T. (2019). The art of coding and thematic exploration in qualitative research. International Management Review, 15(1), 45-55.

Zhou, G., \& Zhang, Z. (2014). A study of the first year international students at a Canadian university: Challenges and experiences with social integration. Canadian and International Education, 43(2), Article 7. https://doi.org/10.5206/cie-eci.v43i2.9253

Zhou, G., Liu, T., \& Rideout, G. (2017). A study of Chinese international students enrolled in the master of education program at a Canadian university: Experiences, challenges, and expectations. International Journal of 
Chinese Education, 6(2), 210-235. https://doi.org/10.1163/22125868-12340081

\section{Copyrights}

Copyright for this article is retained by the author(s), with first publication rights granted to the journal.

This is an open-access article distributed under the terms and conditions of the Creative Commons Attribution license (http://creativecommons.org/licenses/by/4.0/). 